\title{
Artigo/Article
}

\section{Os morcegos e a raiva na região oeste do Estado de São Paulo}

\author{
The bats and rabies in the Western region of the State of São Paulo, Brazil
}

\author{
Avelino Albas ${ }^{1}$, Edson Aroldo Novaes de Souza ${ }^{1}$, Miléia Ricci Picolo ${ }^{1}$, Silvana Regina Favoretto ${ }^{2}$, \\ Adriana Ruckert da Gama ${ }^{3}$ e Miriam Martos Sodré ${ }^{3}$
}

\begin{abstract}
RESUMO
Introdução: O laboratório do Pólo da Alta Sorocabana de Presidente Prudente, SP, em parceria com outras instituições de pesquisa, realizou estudos pertinentes aos morcegos da região oeste do Estado de São Paulo, Brasil. Para tal, foram pesquisadas algumas situações, tais como: a) isolamento do vírus rábico, no período 2006 a 2008; b) as respectivas variantes antigênicas; c) abrigos diurnos do morcego hematófago Desmodus rotundus. Métodos: As amostras para exame foram provenientes de morcegos não hematófagos encaminhadas ao laboratório sendo submetidas aos testes de imunofluorescência direta e prova biológica. As amostras positivas foram caracterizadas antigenicamente por meio do teste de anticorpos monoclonais. Quanto aos morcegos, foram identificados e classificados, e também foi realizado mapeamento de abrigos dos mesmos. Resultados: O laboratório recebeu 1.113 morcegos não hematófagos para diagnóstico laboratorial, sendo $11(1 \%)$ deles positivos, e dentre as amostras positivas, $5(45,5 \%)$ delas tiveram variante antigênica 3 associada ao morcego D. rotundus e $4(36,5 \%)$ foram compatíveis com amostras de morcegos insetívoros. Foram pesquisados 16 abrigos de morcegos hematófagos e observou-se a presença de outras 3 espécies de morcegos não hematófagos convivendo com eles. Conclusões: Os experimentos mostraram que o vírus rábico continua circulando na região com pelo menos 3 variantes antigênicas, e que, a coabitação de morcegos hematófagos com não hematófagos pode ter alguma relação com a disseminação do vírus rábico.
\end{abstract}

Palavras-chaves: Raiva. Morcegos. Diagnóstico laboratorial. Anticorpos monoclonais Tipificação antigênica.

\begin{abstract}
Introduction: The Polo da Alta Sorocabana Laboratory in Presidente Prudente, SP, in partnership with other research institutions, conducted studies related to bats from the western region of the State of Sao Paulo, Brazil. Thus, certain situations were investigated, including: a) isolation of the rabies virus from 2006 to 2008; b) identification of respective antigenic variants; and c) characterization of daytime shelters of Desmodus rotundus vampire bats. Methods: Samples for examination originated from nonhematophagous bats forwarded to the laboratory and subjected to direct fluorescent antibody test and mouse inoculation test. Positive samples were characterized by the monoclonal antibody test. Regarding the bats, they were identified and classified and mapping of their shelters was also performed. Results: The laboratory received 1,113 nonhematophagous bats for rabies diagnosis, 11 (1\%) of which were positives, and among the positive samples, $5(45.5 \%)$ presented antigenic variant 3 (from the bat Desmodus rotundus) and 4 (36.5\%) were compatible with samples derived from Brazilian insectivorous bats. Sixteen vampire bat shelters were investigated and observation confirmed the presence of another 3 species of nonhematophagous bats coexisting with them. Conclusions: The experiments showed that at least 3 antigenic variants of rabies virus are circulating in the region and that the cohabitation of vampire bats with nonhematophagous bats could be related to the dissemination of the rabies virus.
\end{abstract}

Keywords: Rabies. Bats. Laboratorial diagnosis. Monoclonal antibodies. Antigenic typing.

1. Agência Paulista de Tecnologia dos Agronegócios, Pólo da Alta Sorocabana, Presidente Prudente, SP. 2. Instituto Pasteur, São Paulo, SP. 3. Centro de Controle de Zoonoses, Prefeitura de São Paulo, São Paulo, SP

Endereço para correspondência: Dr. Avelino Albas. R. Fernão Sales 555, 19570-000 Regente Feijó, SP. Telefax: 5518 3222-8688.

e-mail: avealbas@yahoo.com.br

Recebido para publicação em 28/06/2010

Aceito em 08/11/2010

\section{INTRODUÇÃO}

Desde 1995, o laboratório do Pólo da Alta Sorocabana foi credenciado pelo Ministério da Saúde com a finalidade de realizar o diagnóstico laboratorial da raiva para, aproximadamente, 53 municípios que compõem a $10^{\mathrm{a}}$ região administrativa do Estado de São Paulo. Presidente Prudente é a sede administrativa dessa região e, geograficamente, localiza-se a sudoeste de São Paulo, latitude $22^{\circ} 07^{\prime} 04^{\prime \prime}$ e longitude $51^{\circ} 22^{\prime} 57^{\prime \prime}$.

A notificação dos casos de raiva em morcegos aumentou significativamente nos últimos anos, e particularmente preocupantes, são os registros de casos em morcegos não hematófagos, pois sua adaptação ao ambiente urbano pode ocasionar infecções de animais de estimação e pessoas ${ }^{1}$.

Na década de 1996 a 2005, houve diminuição no número de casos de raiva canina em $72 \%$, nas Américas, sem contar os países da América do Norte. Porém, houve aumento de casos em relação à raiva silvestre de aproximadamente $445 \%$, com variação de 46 casos, em 1996, para 251, em 2005, sendo que a maioria foi formada por morcegos hematófagos e não hematófagos ${ }^{2}$.

Albas cols ${ }^{3}$ realizaram estudo da presença do vírus rábico, na região de Presidente Prudente, SP, no período de 1996 a 2003, e detectaram a presença de 74 amostras positivas, sendo que destas, 58 (78,4\%) foram referentes a morcegos não hematófagos.

Vários pesquisadores têm realizado experimentos se utilizando do teste de anticorpos monoclonais ${ }^{47}$.

Ovírusdaraiva pareceter,nosmorcegoshematófagos, o melhor e mais eficiente veículo de propagação, uma vez que, para se alimentar, atacam, diariamente, outros animais, que são suas presas e/ou seus próprios companheiros, nas interações sociais agressivas ${ }^{8,9}$.

Vários autores estudaram o comportamento desses morcegos, bem como, sua participação na transmissão da raiva; para tal, realizaram experimentos observando vários tipos de abrigos diurnos do Desmodus rotundus ${ }^{9-12}$. 
O objetivo deste trabalho é estudar os morcegos, na região oeste do Estado de São Paulo, relacionados com a disseminação do vírus rábico.

\section{MÉTODOS}

\section{Amostras para exame e testes para diagnóstico laboratorial da raiva}

As amostras para exame foram provenientes de morcegos não hematófagos encaminhados ao Laboratório da Agência Paulista de Tecnologia dos Agronegócios (APTA), Pólo da Alta Sorocabana de Presidente Prudente, SP. Foram utilizados fragmentos do sistema nervoso central para o preparo de lâminas e inóculos. Para o diagnóstico laboratorial da raiva, empregou-se o teste de imunofluorescência direta, conforme descrito por Dean \& Abelseth $^{13}$ e a prova biológica (inoculação em camundongos), de acordo com o método preconizado por Koprowski ${ }^{14}$. Ambas as técnicas são recomendadas pela Organização Mundial da Saúde.

TABELA 1 - Morcegos encaminhados para diagnóstico laboratorial da raiva, no período de 2006 a 2008, e os casos positivos, região de Presidente Prudente, Estado de São Paulo.

\begin{tabular}{|c|c|c|c|c|c|c|c|c|}
\hline \multirow[b]{3}{*}{ Família/espécie } & \multicolumn{6}{|c|}{ Ano } & & \\
\hline & \multicolumn{2}{|c|}{2006} & \multicolumn{2}{|c|}{2007} & \multicolumn{2}{|c|}{2008} & \multicolumn{2}{|c|}{ Morcegos } \\
\hline & $\mathrm{N}$ & $\mathrm{P}$ & $\mathrm{N}$ & $\mathrm{P}$ & $\mathrm{N}$ & $\mathrm{P}$ & $\mathrm{n}^{\mathrm{o}}$ & $\%$ \\
\hline \multicolumn{9}{|l|}{ Molossidae } \\
\hline Cynomops abrasus & & & 1 & & 1 & & 2 & 0,2 \\
\hline Cynomops planirostris & 1 & & 1 & & 1 & & 3 & 0,3 \\
\hline Eumops auripendulus & & & 1 & & 1 & & 2 & 0,2 \\
\hline Eumops glaucinus & 16 & & 22 & & 21 & & 59 & 5,3 \\
\hline Eumops perotis & 1 & & 1 & & 3 & & 5 & 0,5 \\
\hline Molossops planirostris & & & & & 1 & & 1 & 0,1 \\
\hline Molossus molossus & 99 & & 141 & & 163 & & 403 & 36,2 \\
\hline Molossus rufus & 136 & & 146 & & 216 & & 498 & 44,6 \\
\hline Nyctinomops laticaudatus & 2 & & 1 & & 1 & & 4 & 0,4 \\
\hline Nyctinomops macrotis & & & 1 & & & & 1 & 0,1 \\
\hline Tadarida brasiliensis & & & 1 & & & & 1 & 0,1 \\
\hline \multicolumn{9}{|l|}{ Noctilionidae } \\
\hline Noctilio albiventris & & & 1 & & 1 & & 2 & 0,2 \\
\hline \multicolumn{9}{|l|}{ Phyllostomidae } \\
\hline Artibeus fimbriatus & & & 1 & & 1 & & 2 & 0,2 \\
\hline Artibeus jamaicensis & 1 & & 1 & & & & 2 & 0,2 \\
\hline Artibeus lituratus & 5 & & 7 & 2 & 13 & 1 & 28 & 2,5 \\
\hline Carollia perspicillata & & & & & 1 & & 1 & 0,1 \\
\hline Glossophaga soricina & 1 & & & 1 & & & 2 & 0,2 \\
\hline Platyrrhinus lineatus & 2 & & 1 & & 2 & & 5 & 0,5 \\
\hline Phyllostomus hastatus & 1 & & & & & 1 & 0,1 & \\
\hline \multicolumn{9}{|l|}{ Vespertilionidae } \\
\hline Eptesicus diminutus & & & 1 & & 3 & 1 & 5 & 0,5 \\
\hline Eptesicus furinalis & 7 & & 10 & 1 & 1 & & 19 & 1,7 \\
\hline Lasiurus blossevillii & 3 & 1 & 8 & & 9 & & 21 & 1,8 \\
\hline Lasiurus cinereus & 2 & & 1 & & 7 & & 10 & 0,9 \\
\hline Lasiurus ega & 1 & 1 & 6 & & 13 & & 21 & 1,8 \\
\hline Myotis levis & & & & & 1 & & 1 & 0,1 \\
\hline Myotis nigricans & 1 & 1 & 3 & & 7 & 2 & 14 & 1,2 \\
\hline Total & 279 & 3 & 356 & 4 & 467 & 4 & 1.113 & 100,0 \\
\hline
\end{tabular}

N: negativo, P: positivo.

\section{Caracterização antigênica}

Para tipificação antigênica de variantes do vírus rábico, isoladas nas América, foi utilizado um painel com oito anticorpos monoclonais antinucleoproteína fornecidos pelo Centers for Disease Control and Prevention (CDC), Atlanta, GA, USA. Cada amostra foi testada frente a esse painel pelo menos duas vezes, em lotes e dias diferentes, para verificar a reprodutibilidade da caracterização $0^{5,6}$.

\section{Identificação e classificação das espécies de morcegos}

Utilizou-se algumas chaves dicotômicas, onde as características externas e morfométricas, de cada grupo, são analisadas, tais como: tamanho de antebraço, cabeça-corpo, orelha, membrana interfemural, arcada dentária, cor de pelo, presença ou não de apêndice nasal e de outras estruturas que possam distinguir cada espécie ${ }^{15-17}$.

\section{Métodos de captura de morcegos}

Com base na orientação do Ministério da Saúde, conforme Manual de Manejo e Controle da Fundação Nacional de Saúde ${ }^{8}$, que dependendo do habitat das colônias, se aplicou o melhor método de captura: manual, com puçá ou coador ou ainda com redes. Essas redes, mais usadas nas capturas, são do tipo rede de pesca, com malhas pequenas, em torno de $2 \mathrm{~cm}$, e que foram preparadas e expostas junto aos abrigos. As espécies capturadas, após diagnóstico laboratorial da raiva, foram congeladas em freezer a $-20^{\circ} \mathrm{C} \mathrm{e}$, em seguida, encaminhadas ao Centro de Controle de Zoonoses (CCZ), da Prefeitura Municipal de São Paulo, para serem identificadas e classificadas.

\section{Mapeamento de abrigos dos morcegos}

Para tal, fez-se uso de um aparelho GPS da marca Garmin, modelo Etrex Legend que determinou as coordenadas geográficas.

\section{Considerações éticas}

Quanto à ética, este experimento seguiu a Lei $\mathrm{n}^{\mathrm{o}} 11.794$ de 8 de outubro de 2008 que trata do procedimento para uso científico de animais.

\section{RESULTADOS}

No período de 2006 a 2008, o laboratório recebeu 1.113 amostras de morcegos não hematófagos para diagnóstico laboratorial da raiva. A análise demonstrou que 11 (1\%) delas foram positivas e, dentre as positivas, $4(36,4 \%)$ pertenceram à família Phyllostomidae e 7 (63,6\%) à família Vespertilionidae. Quanto à fauna de morcegos recebidos, a maioria pertenceu ao gênero Molossus, num total de 901 (80,9\%) exemplares e, desses, 403 (44,3\%) foram identificados como Molossus molossus e 498 (55,7\%) como Molossus rufus (Tabela 1).

Quando se fez uso da técnica de anticorpos monoclonais, nas 11 amostras positivas, $5(45,5 \%)$ delas apresentaram variante 3 compatível com amostras isoladas de morcegos D. rotundus, prevalecendo a espécie Artibeus lituratus; 4 (36,5\%) amostras foram associadas com às de morcegos insetívoros, predominando 
TABELA 2 - Isolamento do vírus rábico em morcegos e classificação por espécie, município e variante antigênica, no período de 2006 a 2008, região de Presidente Prudente, Estado de São Paulo.

\begin{tabular}{|c|c|c|c|}
\hline Amostra & Espécie & Município & Variante \\
\hline $032 / 06$ & Lasiurus blossevillii & Presidente Prudente & $6^{*}$ \\
\hline $056 / 06$ & Lasiurus ega & Álvares Machado & $3^{* *}$ \\
\hline $367 / 06$ & Myotis nigricans & Osvaldo Cruz & $* * *$ \\
\hline $111 / 07$ & Eptesicus furinalis & Dracena & *** \\
\hline $202 / 07$ & Glossophaga soricina & Osvaldo Cruz & 3 \\
\hline $305 / 07$ & Artibeus lituratus & Presidente Prudente & 3 \\
\hline $308 / 07$ & Artibeus lituratus & Presidente Prudente & 3 \\
\hline $062 / 08$ & Artibeus lituratus & Dracena & 3 \\
\hline $161 / 08$ & Myotis nigricans & Santo Expedito & $* * *$ \\
\hline $370 / 08$ & Eptesicus diminutus & Dracena & Incompatível com o painel \\
\hline $466 / 08$ & Myotis nigricans & Dracena & $* * *$ \\
\hline
\end{tabular}

a espécie Myotis nigricans. Das 2 amostras restantes, 1 (9\%) delas foi a variante 6 compatível com amostras do gênero Lasiurus e a outra (9\%) foi incompatível com o perfil do painel de anticorpos monoclonais préestabelecido no painel. (Tabela 2).

Quanto aos 16 abrigos diurnos de morcegos, 8 (50\%) deles se caracterizaram, principalmente, sob a forma de casas abandonadas e em seguida foram os túneis em número de 4 (25\%). Encontrou-se $2(12,5 \%)$ abrigos em forma de bueiro; 1 (6,2\%) como ponte e $1(6,2 \%)$ foi caracterizado como barracão subterrâneo (Figura 1 e Tabela 3).

Em relação às espécies encontradas nos abrigos, foram capturados 126 exemplares, sendo que em apenas 2 deles (abrigo 1 e abrigo 7) não foi capturado morcego hematófago da espécie Desmodus rotundus. A espécie Carollia perspicillata foi a mais coletada, em número de 75 (59,5\%), seguida da hematófaga Desmodus rotundus com 41 (32,5\%) exemplares, da Glossophaga soricina com 8 (6,4\%) e, por último, a espécie Platyrrhinus lineatus com $2(1,6 \%)$ exemplares, conforme mostra a Tabela 4.

Todas as espécies coletadas foram submetidas ao diagnóstico laboratorial da raiva e $100 \%$ delas foram negativas.

TABELA 3 - Caracterização dos abrigos diurnos de morcegos observados na região de Presidente Prudente, no período de 2006 a 2008, Estado de São Paulo.

\begin{tabular}{|c|c|c|c|}
\hline Abrigo & Município (nome do local) & Tipo & $\begin{array}{c}\text { Coordenadas } \\
\text { geográficas }\end{array}$ \\
\hline \multirow[t]{2}{*}{1} & Pirapozinho (Fazenda Morada do Sol) & barracão subterrâneo & S $22^{\circ} 38^{\prime} 50.9^{\prime \prime}$ \\
\hline & & & W $51^{\circ} 37^{\prime} 56.6^{\prime \prime}$ \\
\hline \multirow[t]{2}{*}{2} & Anhumas (Ponte sobre rodovia) & túnel & S $22^{\circ} 11^{\prime} 56.7^{\prime \prime}$ \\
\hline & & & W $51^{\circ} 24^{\prime} 42.6^{\prime \prime}$ \\
\hline \multirow[t]{2}{*}{3} & Pirapozinho (Ponte sobre rodovia) & túnel & $\mathrm{S} 22^{\circ} 15^{\prime} 32.8^{\prime \prime}$ \\
\hline & & & W $51^{\circ} 26^{\prime} 55.9^{\prime \prime}$ \\
\hline \multirow[t]{2}{*}{4} & Pirapozinho (Ponte sobre rodovia) & túnel & $\mathrm{S} 22^{\circ} 12^{\prime} 35.6^{\prime \prime}$ \\
\hline & & & W $51^{\circ} 25^{\prime} 33.7^{\prime \prime}$ \\
\hline \multirow[t]{2}{*}{5} & Paulicéia (Fazenda Corpus Cristi) & casa abandonada & $\mathrm{S} 21^{\circ} 10^{\prime} 56.7^{\prime \prime}$ \\
\hline & & & W $51^{\circ} 47^{\prime} 29.9^{\prime \prime}$ \\
\hline \multirow[t]{2}{*}{6} & Regente Feijó (Sítio Sto Antônio) & casa abandonada & $S 22^{\circ} 15^{\prime} 19.7^{\prime \prime}$ \\
\hline & & & W $51^{\circ} 21^{\prime} 15.1^{\prime \prime}$ \\
\hline \multirow[t]{2}{*}{7} & Rancharia (Fazenda NR) & bueiro & S $22^{\circ} 5^{\prime} 35^{\prime \prime}$ \\
\hline & & & W $50^{\circ} 49^{\prime} 40.6^{\prime \prime}$ \\
\hline \multirow[t]{2}{*}{8} & Nantes (Sítio Pingo D’agua) & casa abandonada & S $22^{\circ} 39^{\prime} 24.1^{\prime \prime}$ \\
\hline & & & W $51^{\circ} 13^{\prime} 40.9^{\prime \prime}$ \\
\hline \multirow[t]{2}{*}{9} & Indiana (Sítio Sta Maria) & casa abandonada & S $22^{\circ} 5^{\prime} 23.8^{\prime \prime}$ \\
\hline & & & W $51^{\circ} 15^{\prime} 51.2^{\prime \prime}$ \\
\hline \multirow[t]{2}{*}{10} & Taciba (Ponte sobre rodovia) & ponte & S $22^{\circ} 39^{\prime} 36^{\prime \prime}$ \\
\hline & & & W $51^{\circ} 23^{\prime} 9^{\prime \prime}$ \\
\hline \multirow[t]{2}{*}{11} & Estrela do Norte (Ponte sobre rodovia) & bueiro & $\mathrm{S} 22^{\circ} 32^{\prime} 52^{\prime}$ \\
\hline & & & W $51^{\circ} 41^{\prime} 19.5^{\prime \prime}$ \\
\hline \multirow[t]{2}{*}{12} & Martinópolis (Casa abandonada) & casa abandonada & S $21^{\circ} 57^{\prime} 14.2^{\prime \prime}$ \\
\hline & & & W $51^{\circ} 6^{\prime} 37.6^{\prime \prime}$ \\
\hline \multirow[t]{2}{*}{13} & Anhumas (Estância São Luiz) & casa abandonada & $\mathrm{S} 22^{\circ} 28^{\prime} 5^{\prime \prime}$ \\
\hline & & & W $51^{\circ} 24^{\prime} 43^{\prime \prime}$ \\
\hline \multirow[t]{2}{*}{14} & Álvares Machado (Sítio N. S. Aparecida) & casa abandonada & S $22^{\circ} 11 ’ 27.8^{\prime \prime}$ \\
\hline & & & W $51^{\circ} 32^{\prime} 39.6^{\prime \prime}$ \\
\hline \multirow[t]{2}{*}{15} & Presidente Prudente (Estação da SABESP) & túnel & $\mathrm{S} 22^{\circ} 5^{\prime} 35^{\prime \prime}$ \\
\hline & & & W $51^{\circ} 17^{\prime} 11.7^{\prime \prime}$ \\
\hline \multirow[t]{2}{*}{16} & Presidente Bernardes (Fazenda Imperial) & casa abandonada & S $21^{\circ} 51^{\prime} 53.7^{\prime \prime}$ \\
\hline & & & W $51^{\circ} 31^{\prime} 51.8^{\prime \prime}$ \\
\hline
\end{tabular}




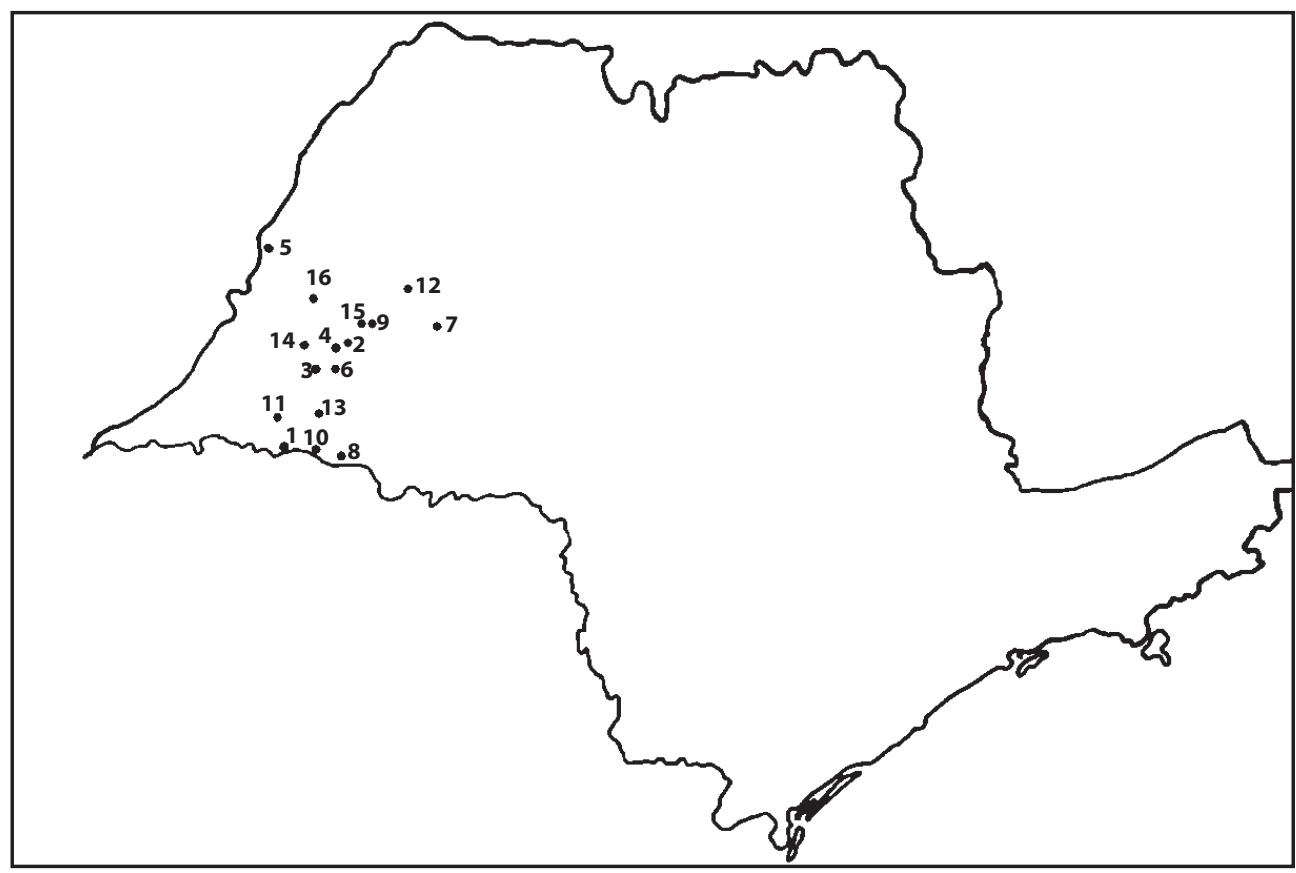

FIGURA 1 - Mapeamento dos abrigos diurnos de morcegos dos municípios da região de Presidente Prudente, SP, assim especificados: 1, 3 e 4: Pirapozinho. 2 e 13: Anhumas. 5: Paulicéia. 6: Regente Feijó. 7: Rancharia. 8: Nantes. 9: Indiana. 10: Taciba. 11: Estrela do Norte. 12: Martinópolis. 14: Álvares Machado. 15: Presidente Prudente. 16: Presidente Bernardes.

TABELA 4 - Classificação e quantidade dos morcegos encontrados em abrigos observados na região de Presidente Prudente, no período de 2006 a 2008 , Estado de São Paulo, Brasil.

\begin{tabular}{lrrrrrrrrrrrrrrrrrrr}
\hline Espécie & A1 & A2 & A3 & A4 & A5 & A6 & A7 & A8 & A9 & A10 & A11 & A12 & A13 & A14 & A15 & A16 & Total \\
\hline Carollia perspicillata & 3 & 1 & 12 & 2 & 7 & 5 & 5 & 3 & 5 & 3 & 3 & 10 & 2 & - & - & 14 & 75 \\
\hline Desmodus rotundus & - & 1 & 9 & 6 & - & 3 & 2 & 2 & 1 & 2 & 1 & 2 & 2 & 2 & 3 & 5 & 41 \\
\hline Glossophaga soricina & - & - & - & - & 5 & - & - & - & - & - & 1 & 1 & 1 & - & - & - & 8 \\
\hline Platyrrhinus lineatus & - & - & - & - & 1 & - & - & - & - & - & - & 1 & - & - & - & - & 2 \\
\hline Total & $\mathbf{3}$ & $\mathbf{2}$ & $\mathbf{2 1}$ & $\mathbf{8}$ & $\mathbf{1 3}$ & $\mathbf{8}$ & $\mathbf{7}$ & $\mathbf{5}$ & $\mathbf{6}$ & $\mathbf{5}$ & $\mathbf{5}$ & $\mathbf{1 4}$ & $\mathbf{5}$ & $\mathbf{2}$ & $\mathbf{3}$ & $\mathbf{1 9}$ & $\mathbf{1 2 6}$ \\
\hline A: abrigo. & & & & & & & & & & & &
\end{tabular}

\section{DISCUSSÃO}

Nos últimos anos, os casos de raiva em morcegos tem aumentado em São Paulo e outros estados do Brasil ${ }^{3,18-20}$. Segundo Sodré cols ${ }^{20}$, a nova lista de morcegos positivos para raiva consiste de 41 espécies pertencentes a 25 gêneros e três famílias: Phyllostomidae (43,9\%), Vespertilionidae (29,3\%) e Molossidae (26,8\%). O experimento realizado na região de Presidente Prudente, SP diverge um pouco desses achados, apresentando maioria na espécie Vespertilionidae (63,6\%) e em segundo a família Phyllostomidae (36,4\%) e nenhum caso na família Molossidae, apesar do grande número de amostras analisadas. Este experimento se aproximou mais dos resultados encontrados por Queiroz cols ${ }^{21}$ que, na região noroeste do Estado de São Paulo, encontraram 70\% de morcegos insetívoros contaminados com o vírus e $30 \%$ em frugívoros; e também, como em Presidente Prudente, nenhum caso foi registrado em morcego hematófago.

Favoretto cols ${ }^{6}$ realizaram tipificação antigênica de amostras brasileiras do vírus rábico isolado de animais e humanos, no período de 1989 a 2000, e detectaram maior variabilidade entre as amostras isoladas de morcegos insetívoros e a variante mais comum isolada, entre as espécies, foi a variante 3 (D. rotundus), observação esta, que corrobora parcialmente com os resultados encontrados na região oeste do Estado de São Paulo, uma vez que essa região, tem detectado acentuado aumento no número de variantes que se associam com amostras de morcegos insetívoros.

A variante 3 tem sido identificada em várias espécies animais, principalmente cães, gatos e bovinos ${ }^{22-24}$. Smith ${ }^{7}$ recomenda especial atenção ao morcego $D$. rotundus que mantém o vírus em espécies animais terrestres. No caso da morte de uma pessoa, na região de Presidente Prudente, em 2001, após exaustiva investigação epidemiológica, concluiu-se que a vítima adquiriu a doença pela agressão de um gato, que deve ter adquirido o vírus de um morcego não hematófago portador da variante 3 , associada ao $D$. rotundus, uma vez que a tipificação do vírus que vitimou a mulher foi desta variante $^{25}$.

Diferentemente de estudo anterior realizado, também, na região de Presidente Prudente ${ }^{4}$, onde se identificou apenas a variante 3 (D. rotundus) e a variante 4 (Tadarida brasiliensis), esta pesquisa mostra o aparecimento de várias amostras identificadas com morcegos insetívoros do Brasil, principalmente, morcegos dos gêneros Eptesicus e Myotis. Todas as amostras referentes ao gênero Artibeus foram portadoras da variante 3, resultado esse que corrobora o encontrado por Delpietro cols ${ }^{26}$, em 1977.

Quanto aos abrigos diurnos de morcegos hematófagos estudados, todos eles (100\%), caracterizaram-se como artificiais e 50\% como 
casas abandonadas, e nenhum abrigo natural. Da Rocha ${ }^{9}$, estudando esses mesmos tipos de abrigos nas regiões centro-sul e centro-leste do Estado de São Paulo, encontrou 54,5\% de abrigos artificiais, envolvendo casas e bueiros e $45,5 \%$ foram abrigos naturais, como cavernas e grutas (estes tipos de abrigos são praticamente inexistentes na região oeste do Estado de São Paulo).

Segundo Cortes cols ${ }^{10}$, os abrigos artificiais geralmente fornecem boas condições microclimáticas (temperatura estável, alta umidade e baixa luminosidade), costumam ser amplos, de fácil acesso para os morcegos e estão situados próximos dos alimentos (o que reduz gastos energéticos com deslocamento e exposição aos predadores).

Todas as espécies de morcegos coletadas e submetidas ao diagnóstico laboratorial da raiva foram $100 \%$ negativas. Resultados estes, que corroboram com a pesquisa de Rupprecht ${ }^{27}$, segundo a qual, os morcegos capturados em vôos, sugerem menos que $1 \%$ de positividade.

Os resultados encontrados reforçam a necessidade dos órgãos responsáveis pelo controle da raiva, na região, concentrarem esforços no sentido de encaminhar maior número possível de amostras para análise laboratorial, uma vez que o vírus rábico se faz presente na região, principalmente, em morcegos não hematófagos que têm contatos diretos com animais domésticos e pessoas, submetendo os mesmos ao risco de contágio. $\mathrm{O}$ estudo pertinente às variantes antigênicas do vírus rábico demonstrou mudanças neste perfil com o aparecimento de várias amostras identificadas com morcegos insetívoros do Brasil, sendo que em estudos anteriores havia predomínio da variante 3. Com relação aos abrigos estudados, conclui-se que pode haver alguma relação na disseminação do vírus rábico entre morcegos hematófagos e não hematófagos, tendo em vista a coabitação existente entre as espécies.

\section{CONFLITO DE INTERESSE}

Os autores declaram não haver nenhum tipo de conflito de interesse no desenvolvimento do estudo.

\section{SUPORTE FINANCEIRO}

FAPESP, processo no 05/59818-6.

\section{REFERÊNCIAS}

1. Batista HBCR, Franco AC, Roehe PM. Raiva: uma breve revisão. Acta Sci Vet 2007; 35:125-144.

2. Organização Panamericana da Saúde. Centro Panamericano de Febre Aftosa. Organização Mundial de Saúde. Sistema de Informação Regional de Vigilância Epidemiológica da Raiva nas Américas. [acesso: 01 jun 2010]. Disponível em: http://siepi.panaftosa.org.br/anuais.aspx.

3. Albas A, Zocolaro PT, Rosa TZ, Cunha SEM. Diagnóstico laboratorial da raiva na região oeste do Estado de São Paulo. Rev Soc Bras Med Trop 2005; 38:493-495.

4. Albas A, Edson ANS, Lourenço RA, Favoretto SR, Sodré MM. Perfil antigênico do vírus da raiva isolado de diferentes espécies de morcegos não hematófagos da Região de Presidente Prudente, Estado de São Paulo. Rev Soc Bras Med Trop 2009; 42:15-17.

5. Diaz AM, Papo S, Rodriguez A, Smith JS. Antigenic analysis of rabies-virus isolates from Latin America and the Caribbean. Zent fur Vet B 1994; 41:153-160.

6. Favoretto SR, Carrieri ML, Cunha EMS, Aguiar EAC, Silva LHQ, Sodré MM, et al. Antigenic typing of Brazilian rabies samples isolated from animals and humans, 1989-2000. Rev Inst Med Trop São Paulo 2002; 44:91-95.
7. Smith JS. Monoclonal antibody studies of rabies in insectivorous bats of the United States. Rev Inf Dis 1988; 10 (supl):637-643.

8. Bredt A, Araújo FAA, Caetano-Jr J, Rodrigues MGR, Yoshikawa M, Silva MMS Morcegos em áreas urbanas e rurais: Manual de manejo e controle. Brasília: Fundação Nacional de Saúde; 1998.

9. Rocha FA. Abrigos diurnos, agrupamentos e lesões corporais no morcego hematófago Desmodus rotundus (Chiroptera, Phyllostomidae) do Estado de São Paulo. [Dissertação de Mestrado]. [Botucatu, SP]: Faculdade de Medicina Veterinária e Zootecnia. Universidade Estadual Paulista; 2005. 70p.

10. Cortes VA, Souza LC, Uieda W, Figueiredo AC. Abrigos diurnos e infecção rábica em morcegos de Botucatu, São Paulo, Brasil. Vet e Zoot Sao Paulo 1994; 6:179-186.

11. Taddei VA, Gonçalves CA, Pedro WA, Tadei WJ, Kotait I, Arieta C. Distribuição do morcego hematófago Desmodus rotundus no Estado de São Paulo e a raiva dos animais domésticos. Campinas: Impresso Especial CATI; 1991.

12. Uieda W, Hayashi NM, Gomes LH, Silva MMS. Espécies de quirópteros diagnosticadas com raiva no Brasil. Bol Inst Pasteur 1996; 1:17-36.

13. Dean DJ, Abelseth MK, Atanasiu P. The fluorescent antibody. In: Meslin FX, Kaplan NM, Koprowski H, editors. Laboratory techniques in rabies.Geneva: World Health Organization; 1966. p. 80-87.

14. Koprowski H. Routine laboratory procedures: The mouse inoculation test. In: Meslin FX, Kaplan NM, Koprowski H, editors. Laboratory techniques in rabies. $40^{\text {th }}$ ed. Genebra: World Health Organization; 1966. p. 88-96.

15. Gregorin R, Taddei VA. Chave Artificial para a Identificação de Molossídeos Brasileiros (Mammalia, Chiroptera). Mastoz-Neotrop 2002; 9:13-32.

16. Nowak RM. Walker's Bats of the world. Baltimore: The Johns Hopkins University Press; 2003.

17. Taddei VA. Sistemática de Quirópteros. Bol Inst Pasteur1996; 1:3-15.

18. Cunha EMS, Silva LHQ, Lara MCCSH, Nassar AFC, Albas A, Sodré MM et al. Bat rabies in the north-northwester regions of the State of São Paulo, Brazil: 1997-2002. Rev Saude Publica 2006; 40:1082-1086.

19. Scheffer KC, Carrieri ML, Albas A, Santos HCP, Kotait I, Ito FH. Vírus da raiva em quirópteros naturalmente infectados no Estado de São Paulo, Brasil. Rev Saude Publica 2007; 41:389-395.

20. Sodré MM, Gama AR, Almeida MF. Updated list of bat species positive for rabies in Brazil. Rev Inst Med Trop Sao Paulo 2010; 52:75-81.

21. Queiroz LH, Carvalho C, Buso DS, Ferrari CIL, Pedro WA. Perfil epidemiológico da raiva na região Noroeste do Estado de São Paulo no período de 1993 a 2007. Rev Soc Bras Med Trop 2009; 42:9-14.

22. Ito M, Arai YT, Itou T, Sakai T. Genetic characterization and geographic distribution of rabies viruses isolates in Brazil: Identification of two reservoirs, dogs and vampire bats. Virology 2001; 284:214-222.

23. Roehe PM, Cunha AC, Rodrigues RR, Gonçalves AR, Ribeiro CLG Diagnóstico laboratorial da raiva no Rio Grande do Sul, Brasil. Bol Ofic Sanit Pan $1985 ; 102: 464-475$.

24. Sacramento DRV, Tordo N, Kotait I. Estudo molecular do vírus da raiva isolado no Estado de São Paulo. São Paulo: Anais da 7a Reunião Anual do Instituto Biológico; 1994. p.15.

25. Kotait I. Past In: Raiva humana causada pela variante 3 Desmodus rotundus. Instituto Pasteur São Paulo 2003; 7:3.

26. Delpietro HA, Gury-Dhomen F, Larghi OP, Mena-Segura C, Abramo L Monoclonal antibody characterization of rabies virus strains isolated in the River Plate Basin. Zent Vet 1977; 44:477-483.

27. Rupprecht CE. Evolution of public health recommendations for human rabies prophylaxis after bat exposure in the United States. In: Basgoz N, editor Rethinking rabies risks sharpening clinical skills for a reemergence threat. Boston: Harvard Medical School; 2000. p. 46. 